\title{
Liver transplantation: expanding the donor and recipient pool
}

\author{
Ola Ahmed ${ }^{1}$, M. B. Majella Doyle $\mathrm{e}^{1,2}$ \\ ${ }^{1}$ Department of Abdominal Organ Transplantation Surgery, Washington University School of Medicine, St Louis, MO, USA; ${ }^{2}$ Division of General \\ Surgery, Abdominal Transplantation Section, Barnes-Jewish Hospital, St. Louis, MO, USA \\ Contributions: (I) Conception and design: All authors; (II) Administrative support: All authors; (III) Provision of study materials or patients: All \\ authors; (IV) Collection and assembly of data: All authors; (V) Data analysis and interpretation: All authors; (VI) Manuscript writing: All authors; (VII) \\ Final approval of manuscript: All authors. \\ Correspondence to: Dr. M. B. Majella Doyle. Department of Surgery, Division of Transplantation, Washington University School of Medicine, St \\ Louis, MO 63110, USA. Email: doylem@wustl.edu.
}

\begin{abstract}
Liver transplantation is an exemplar model of complex surgery and the only curative option for patients with end-stage liver disease. Although historically associated with poor outcomes, liver cancer management has also been revolutionised with liver transplantation and in some instances, survival outcomes are comparable to surgical resection. As such, the key elements underpinning the major advances in surgical technique, immunological therapies and allocation policies combined with improved patient and graft survival outcomes have created a huge demand for organ donation. Despite improvements in donor and recipient selection, there is a persistent disparity between organ supply and demand. Candidate wait-list mortality and dropout rates remain problematic and this concern has resulted in increased efforts to expand the donor pool to meet the unmet needs of the population. This is even more challenging when coupled with an ever-growing recipient pool, candidate waiting lists and an ageing population. Over the past two decades, there has been a considerable focus on extended criteria organs, donations after cardiac death and alternative avenues for marginal liver use. With careful donor selection and recipient matching, these livers may help bridge the gap between supply and demand and placate the ever-expanding recipient pool. Here, we present a summary of recent developments by the transplant community addressing the issues of a growing donor and recipient pool.
\end{abstract}

Keywords: Liver transplantation (LT); expanded criteria; donor pool; recipient pool

Submitted Aug 27, 2020. Accepted for publication Nov 20, 2020.

doi: $10.21037 / \mathrm{cco}-20-212$

View this article at: http://dx.doi.org/10.21037/cco-20-212

\section{Introduction}

The number of candidates added to the transplant wait list continues to grow. In 2019, 8,896 liver transplants were performed in the United States (US) and the rate has been gradually increasing over the last decade (1). The current annual transplant rate of adult candidates actively listed on the wait list is $58.7 \%$ in the US and has increased incrementally compared to previous years. Current 1-, 3- and 5-year survival rates are 91.8\%, 83.8\% and $76.1 \%$, respectively, and liver transplantation (LT) is being considered for a growing list of conditions evident by the expanding recipient pool and waiting lists. Despite the benefits of LT, the scarcity of organs is a universal concern and there have been several attempts by the transplant community to propose strategies to overcome the deficit. This has led to the consideration of livers which were previously considered unsuitable for transplantation and efforts to optimize "marginal" organs using innovative machine technology. We, herein, provide a brief overview of the existing approaches by the transplant community to expand the donor and recipient pool for LT. 


\section{Extended criteria donation to increase the donor pool}

The disparity between supply and demand has led to the consideration of extended criteria donor (ECD) liver allografts or "marginal donors" which do not meet the traditional criteria for organ donation. The aging population, longer life expectancy rates and the rising incidence of several metabolic conditions such as obesity, diabetes and fatty liver disease are all important factors contributing to poor donor quality. Such issues are projected to decrease donor liver utilisation rates from $78 \%$ to $44 \%$ if ECDs are not included in the pool (2). While these organs were previously avoided due to the fear of primary nonfunction (PNF) or delayed graft function (DGF), they are now increasing used with the goal of improving access to transplantable organs (3). The underlying concern is the graft's susceptibility to ischemia/reperfusion during the transplantation process, adding to graft dysfunction and poor regeneration (4). Despite this risk, ECDs have played an important role in expanding the donor liver pool with compelling evidence demonstrating their ability to reduce wait list mortality and exhibit recipient outcomes comparable to standard liver donations $(5,6)$. There is no universally accepted definition for what constitutes an ECD, however, frequently cited characteristics are advanced donor age, donation after cardiac death (DCD), hepatic steatosis, split liver transplantation (SLT), and donors with an infectious risk or previous malignancy $(3,7,8)$.

\section{Accepting donors with an advanced age}

The use of livers from older donors is becoming more frequent in modern practice, despite the concern of DGF during the immediate post-operative period $(7,9,10)$. No clear age cut-off exists and several transplant units are expanding that which is considered an acceptable donor age in an effort to match the increased demand to the ageing population demographic and available donor pool (11). In $2014,8 \%$ of liver donors from the US were 65 years and older and this group increased further to $10 \%$ in recent Organ Procurement and Transplantation Network (OPTN) data $(12,13)$. In a report from the European Liver Transplant Registry, Adam et al. observed that $29 \%$ of donors were older than 60 years and $11 \%$ were 65 years or older (14). Some studies have reported acceptable outcomes in livers from older donors. In an early study by Zapletal et al. comparing liver allografts from donors both older and younger than 80 years, comparable results were achieved in the postoperative course and older livers grafts were functionally stable at discharge (15). Several other units mirrored similar results in liver allografts from donors over 60 years and in some studies favourable outcomes were achieved from donors older than 70 years as the transplant community continues to explore an acceptable upper age limit (16-18). In a recent study using the United Network for Organ Sharing (UNOS) database, Haugen et al. reported a significantly lower 5 -year cumulative mortality rate for patients who accepted livers from donors $>70$ years when compared to a matched control group who declined the same offer (23\% vs. $41 \%$ ) and the authors demonstrated a substantial long-term survival benefit in the former group (19). Despite these favourable outcomes, judicious matching of older donors is paramount as these grafts are more susceptible to ischemia reperfusion injuries, biliary complications, a slight preponderance for hepatic artery thrombosis and the risks are particularly heightened in donors with hepatitis $C(17,20,21)$.

\section{Increasing DCD}

Livers from donors with irreversible brain injury, not meeting the criteria for brain death, have resulted in the expansion of the donor pool. A study by Saidi et al. reported an increase in the utility of DCD organs from $4.9 \%$ to $11.7 \%$ during a 10 -year study period (22). In the case of LT, recent OPTN data suggests an increase from $4.8 \%$ to 6.9\% in DCD livers between 2008 and 2018 (12). Several studies comparing DCD livers with standard brain-dead donors (DBD) have demonstrated poorer allograft and patient survival rates in the latter. This is likely related to the longer ischemia time associated with DCD donors, commencing from the time of extubation until cold perfusion, which can be highly variable. A large multicentre study of 2,572 liver transplants comparing DCD and DBD livers identified that 3 -year graft loss and recipient mortality were twice as high with DCDs (23). In contrast, a study by Taner et al. noted no differences in 1-, 3- and 5-year patient survival rates between DBD and DCD groups and similar comparable outcomes for graft survival (24). In an effort to determine factors leading to graft loss, the authors identified a link between the asystole to cross clap duration and the development of ischemic cholangiopathy, an important and feared consequence of DCDs. Nonetheless, DCDs can significantly and safely expand the donor pool when used with caution, adhering to a warm ischemia time less than 
30 minutes, using donors younger than 50 years and limiting cold ischemia time $(7,8)$. Future efforts to minimize ischemia times and expand the upper age cut-off will further increase the utility of DCD livers and expand the donor pool.

\section{The use of steatotic livers}

The rising incidence of obesity and metabolic syndromes has led to the commensurate rise in non-alcoholic fatty liver disease (NAFLD), with a population prevalence of up to $30 \%$ in Western societies $(25,26)$. These rising incidences and prevalence rates have seen parallel increases in potential donors with hepatic steatosis. Traditionally, steatotic allografts were avoided in LT for posing significant clinical challenges in terms of early graft dysfunction and PNF. An early study by Spitzer and colleagues analyzing a large US registry of transplant recipients conclusively established that livers with $30 \%$ or greater macrovesicular steatosis were associated with lower 1-year survival rates (27). Similar studies have demonstrated unfavourable outcomes in the use of grafts with moderate (30-60\%) and severe $(>60 \%)$ steatosis, largely due to the increased susceptibility of steatotic grafts to ischemia reperfusion injuries $(28,29)$. However, in an effort to further expand the donor pool, fatty livers are increasingly considered for transplantation and form a major component for ECDs. In well matched cases, mild steatosis may have a minimal impact on reperfusion injury and post-transplant hepatic functionality. A study by Dutkowski and colleagues analysed both US and European liver transplant registries and determined grafts with microvesicular and $30 \%$ or less macrovesicular steatosis can be used safely with outcomes comparable to non-steatotic livers (30). Acceptable outcomes were also achieved in steatosis greater than $30 \%$ with careful risk adjustment, although this remains controversial. Similar studies assessing the suitability of steatotic grafts have also considered the use of moderate to severely steatotic allografts with somewhat acceptable post-transplant outcomes, provided they are supplied by low-risk donors $(31,32)$. Continuing to extend the upper limits of steatosis and define the acceptability of steatotic grafts will still be a matter for debate, however, the integration of these grafts into the donor pool has been a key element in providing more livers for transplant.

\section{Considering donors with an increased infectious risk}

The use of donors with exposure to hepatitis B (HBV) or
C (HCV) virus has been more acceptable in current times, albeit previously met with strong objection due to initial concerns regarding the introduction of aggressive viral strains to immunosuppressed recipients. In the context of $\mathrm{HCV}$, there has been a shift in previous attitudes and recent OPTN data reports an increase in the number of livers recovered from hepatitis $\mathrm{C}$ positive donors and the number of wait-list candidates willing to accept these livers (12). Rigorous matching remains pertinent and younger donors are preferred due to the fear of increased fibrosis in recipients when older HCV positive donors are used (33). Hepatitis C positive recipients transplanted with positive donors have demonstrated comparable outcomes to those receiving $\mathrm{HCV}$ negative livers $(34,35)$. In an effort to further expand the donor pool for all patients, transplanting $\mathrm{HCV}$ positive livers into $\mathrm{HCV}$ negative patients, with the addition of effective antiviral regimens, has seen some promise in terms of long-term outcomes. Chhatwal and colleagues report compelling evidence demonstrating that accepting $\mathrm{HCV}$ positive livers for all donors may increase life expectancy and decrease wait-list mortality (36). Additionally, a recent study by Cotter and colleagues analysing data from 2008 to 2018 reports increased 3-year graft survival rates from $79 \%$ to $88 \%$ in $\mathrm{HCV}$ negative donors receiving $\mathrm{HCV}$ positive livers and direct-acting antiviral therapies (37). Similarly, the increased use of organs from HBV positive donors has the potential to expand the donor pool. In a study by Cholongitas and colleagues, recipients without prior exposure to HBV receiving antiviral prophylaxis showed excellent outcomes following transplantation with $\mathrm{HBV}$ positive livers (38). Effective HBV prophylaxis in the form of hepatitis B immunoglobulin or oral antiviral therapy have led to a reduction in HBV transmission and viral recurrence in select donors and some units have included these in their donor pool (39-41). While this practice is still limited to a few centres because of the concern of viral reactivation in recipients, more effective prophylaxis could encourage the inclusion of such grafts for the wider recipient pool.

\section{Split liver grafts}

Splitting livers (SLT) into two potential grafts has been explored as another method to increase donor supply, however, their use has been relatively stable over the last decade (12). This procedure usually involves donating the left lateral segment to a pediatric recipient and transplanting the right trisegment into an adult, although 
splitting the liver into a right and left lobe for two adults has also been described $(7,42)$. It has been estimated that up to $20 \%$ of livers are suitable for splitting, however, the technique is limited to specialist centres due to the complexity of the procedure and the heightened risk of biliary and vascular complications $(42,43)$. A study by Vagefi and colleagues assessing outcomes in SLT recipients reported $93 \%, 77 \%$, and $73 \%$ and $89 \%, 76 \%$, and $65 \%$ overall patient and graft survival rates at 1-, 5and 10-years (44). A similar study by Doyle and colleagues demonstrated $95.5 \%, 89.5 \%$ and $89.5 \% 1-, 5$ - and 10-year survival rates in adults recipients of SLT, comparable to whole organ (WLT) recipients (45). In contrast, a multicentre study by Aseni demonstrated lower 5-year survivals in patients receiving SLT compared to WLT (63.3\% vs. 83.1\%) (46). While SLT continues to be limited to centres with technical expertise, they require high quality grafts to gain acceptable post-operative outcomes and currently only represent $1 \%$ of US liver transplants and $6 \%$ of transplants in Europe $(12,47)$.

\section{Living donor LT (LDLT)}

First reported in the US in 1998, LDLT is an additional mechanism to expand the donor pool and increase organ availability. Both right and left lobes can be used in transplantation with the latter generally reserved for small sized recipients and paediatric patients. A left lobe resection has the added benefit of removing a smaller portion of liver from the living donor. By contrast, the right lobe, mainly reserved for adult patients, accounts for up to two-thirds of the total liver mass and can potentially cause significant harm to the donor if the remnant liver volume is too small or unhealthy to support the metabolic and physiological needs of the recipient. The number of LDLTs has increased slowly over the past 2 decades and recent US liver registry data reports LDLTs accounted for up to $4.4 \%$ of liver donations in $2018(12,48)$. Although modest, the increase in LDLTs has been largely driven by a rise in the number of unrelated directed donors (12). The number of left lobe resections has also decreased corresponding with a parallel rise in right lobe donations. A study by Shah and colleagues demonstrated significantly shorter mean waiting times between right lobe donations and patients awaiting grafts from deceased donors (49). Although LDLT has the advantage of optimizing the timing of surgery, comprehensive donor work-up and minimizing cold ischemia and organ transport times, the process still poses a risk to the donor and can subject a healthy person to a substantial burden (50). Overall donor mortality rates range from $0.2 \%$ to $0.8 \%$ with some studies reporting a slight donor survival benefit in right lobe donations (51-53). Graft failure is reported to occur in up to $7.8 \%, 14.6 \%$ and $26.5 \%$ of LDLTs at 1,3 and 5 years with more favourable outcomes demonstrated in non-hepatocellular carcinoma (HCC) diagnoses and Model for End-stage Liver Disease (MELD) scores less than 20 (12). Furthermore, a study by She and colleagues reported, in an analysis of 218 patients, significantly better 5 -year graft survival rates in using right lobe LDLT, albeit comparable 5 -year patient survival rates (54). These findings were contrasted by Olthoff and colleagues who in a large multicentre study of 963 LDLTs demonstrated similar graft survival rates in right and left lobe LDLTs with decreasing rates of graft failure associated with greater centre experience (55). However, despite these promising results several studies have reported inconsistent graft survival rates between LDLT and standard cadaveric liver donations. Some analyses have demonstrated decreased graft survival rates in $\operatorname{LDLT}(56,57)$, while more recent studies appear to demonstrate similar long-term 10-year survival rates between patients receiving grafts from living donors and deceased donor grafts (55). For this reason, LDLT is reserved for high volume centres with specialist expertise due to the complexities of the procedure which requires a deep understanding of the physiological requirements of the graft to ensure sufficient hepatic regeneration and minimize donor risk.

\section{Machine perfusion to optimise liver quality}

The recent arrival of $e x$-vivo machine perfusion techniques is beginning to change the landscape of how "marginal" livers are utilized and has the potential to fully expand the donor pool and reduce liver discard. Hypothermic and normothermic machine perfusion technologies have shown promising results in minimising injury to DCD grafts and steatotic livers $(58,59)$. Schlegel and colleagues provided 5 -year outcome data on patients receiving DCD liver transplants following treatment with hypothermic oxygen perfusion prior to transplantation. Outcomes of treated DCD livers were similar to DBD and superior to untreated DCDs with significantly less graft loss events (58). A recent study reported similar encouraging results in transplanting previously rejected liver allografts following the application of normothermic machine perfusion (60). While the optimal temperature setting continues to be debated, this 
innovation may salvage various extended criteria allografts and modify their risk for routine use, ultimately expanding the donor pool.

\section{Expanding the recipient pool}

Despite several strategies attempting to increase the liver donor pool, the recipient pool continues to expand and wait list mortality remains a concern. The wider acceptance of LT and improved outcomes has allowed clinicians to consider transplanting patients they were historically reluctant to do so. According to OPTN data, alcoholic liver disease, non-alcoholic steatohepatitis (NAFLD) and HCC are the most common conditions leading to LT in the US and the increased public burden of these diseases has contributed to an increased number of patients requiring transplantation (12). The healthcare prevalence of alcoholic liver disease continues to grow. A study by Jinjuvadia and colleagues observed a substantial increase in the number of alcohol-related hospitalizations over an 8-year period (61). In 2018, the proportion of candidates listed for ALD increased considerably from $22.7 \%$ to $29.8 \%$ over a 10 -year period (12). Similarly, NAFLD is becoming more prevalent and has been linked with the alarming growth rate of population obesity (26). Several models have projected this to become the leading cause for LT as more patients progress to decompensated cirrhosis warranting curative intervention. In addition, global trends have demonstrated a rising incidence in the diagnosis of HCC, although the causes of this are still unclear (62). The evidence regarding transplanting HCC patients, particularly since the introduction of the Milan criteria, has been promising for unresectable disease and more patients are being considered for LT and form a substantial portion of the recipient pool $(63,64)$. The proportion of HCC candidates awaiting LT increased from $3.4 \%$ to $9.8 \%$ between 2008 and 2018 (12). There has been some interest in expanding the current eligibility guidelines for HCC. Yao and colleagues report similar LT outcomes in HCC patients with tumours as large as $6.5 \mathrm{~cm}$ or less than 4 nodules smaller than $4.5 \mathrm{~cm}$ and a total tumour diameter less than $8 \mathrm{~cm}$, arguing that the current Milan staging is too restrictive (65). Additionally, the success of chemotherapy has seen several patients with advanced disease downstaged to liver disease within the Milan criteria and meeting eligibility for LT (66). Several other hepatic tumours have been added to the recipient pool with promising results in some units. In a small prospective case-series by Lunsford and colleagues, patients with locally advanced intrahepatic cholangiocarcinoma and stable disease from neoadjuvant therapy had 1-, 3- and 5-year survival rates of $100 \%, 83.3 \%$, and $83.3 \%$ respectively. While the study only involved a small selected group of patients, LT showed promise (67). In addition, despite initial reluctance, some units have started to reconsider LT for colorectal liver metastases (CLM). In a study comparing LT and chemotherapy for nonresectable CLM, LT observed better 5 -year survival rates (56\% vs. 9\%) (68). Although, this has yet to gain widespread acceptance, better expertise in LT and cancer biology could see a rapid expansion in the recipient pool and the inclusion of patients who were previously contraindicated for LT.

\section{Future directions}

The transplant community continues to evolve and active efforts to expand both the donor and recipient pools are in constant motion. LT remains a curative option for a wide spectrum of the population and expertise in surgical technique, immunotherapy and post-operative care are among the several elements underpinning the continually improved outcomes reported internationally. While breakthroughs in machine perfusion and chemotherapy are still underway, the role of social media in increasing awareness of organ donation may be a feasible route. Kumar and colleagues, in collaboration with Facebook, created a mobile application whereby waitlisted candidates were allowed the opportunity to create a post and communicate their experience with organ failure and the need for live organ donation (69). Impressively, candidates who engaged with the app were 6.6 times more likely to have a donor come forward compared with matched controls and the app was received well overall (69). As the boundaries of social media platforms continue to push limits, some have advocated for the increased use of social media billboard approaches and targeted campaigns to shift societal perspectives of organ donation and gain public attention (70).

\section{Conclusions}

In summary, LT is a growing field with boundless potential. The disparity between patients who need a liver transplant and those who receive one is a constant concern, and while significant progress has been made in the field, further efforts from the national and international consortia are warranted. Pre-existing criteria for LT and recipient boundaries are continually challenged and expanded and, 
when coupled with judicious matching and careful patient selection, excellent patient and graft survival results are an endless opportunity.

\section{Acknowledgments}

Funding: None.

\section{Footnote}

Provenance and Peer Review: This article was commissioned by the Guest Editors (Mehmet Akce and Shishir K. Maithel) for the series "Hepatocellular Carcinoma" published in Chinese Clinical Oncology. The article was sent for external peer review organized by the Guest Editors and the editorial office.

Conflicts of Interest: The authors have completed the ICMJE uniform disclosure form (available at http://dx.doi. org/10.21037/cco-20-212). The series "Hepatocellular Carcinoma" was commissioned by the editorial office without any funding or sponsorship. The authors have no other conflicts of interest to declare.

Ethical Statement: The authors are accountable for all aspects of the work in ensuring that questions related to the accuracy or integrity of any part of the work are appropriately investigated and resolved.

Open Access Statement: This is an Open Access article distributed in accordance with the Creative Commons Attribution-NonCommercial-NoDerivs 4.0 International License (CC BY-NC-ND 4.0), which permits the noncommercial replication and distribution of the article with the strict proviso that no changes or edits are made and the original work is properly cited (including links to both the formal publication through the relevant DOI and the license). See: https://creativecommons.org/licenses/by-nc-nd/4.0/.

\section{References}

1. Network OPaT. Tranplants in the US. National data2020. Available online: https://optn.transplant.hrsa.gov/data/ view-data-reports/national-data/

2. Orman ES, Mayorga ME, Wheeler SB, et al. Declining liver graft quality threatens the future of liver transplantation in the United States. Liver Transpl 2015;21:1040-50.
3. Saidi RF. Utilization of expanded criteria donors in liver transplantation. Int J Organ Transplant Med 2013;4:46-59.

4. Busuttil RW, Tanaka K. The utility of marginal donors in liver transplantation. Liver Transpl 2003;9:651-63.

5. Halazun KJ, Quillin RC, Rosenblatt R, et al. Expanding the Margins: High Volume Utilization of Marginal Liver Grafts Among >2000 Liver Transplants at a Single Institution. Ann Surg 2017;266:441-9.

6. Barshes NR, Horwitz IB, Franzini L, et al. Waitlist Mortality Decreases with Increased Use of Extended Criteria Donor Liver Grafts at Adult Liver Transplant Centers. Am J Transplant 2007;7:1265-70.

7. deLemos AS, Vagefi PA. Expanding the donor pool in liver transplantation: Extended criteria donors. Clin Liver Dis (Hoboken) 2013;2:156-9.

8. Vodkin I, Kuo A. Extended Criteria Donors in Liver Transplantation. Clin Liver Dis 2017;21:289-301.

9. Kauffman HM, McBride MA, Rosendale JD, et al. Trends in organ donation, recovery and disposition: UNOS data for 1988-1996. Transplant Proc 1997;29:3303-4.

10. Routh D, Sharma S, Naidu CS, et al. Comparison of outcomes in ideal donor and extended criteria donor in deceased donor liver transplant: A prospective study. Int J Surg 2014;12:774-7.

11. Alkofer B, Samstein B, Guarrera JV, et al. Extended-donor criteria liver allografts. Semin Liver Dis 2006;26:221-33.

12. Kwong A, Kim WR, Lake JR, et al. OPTN/SRTR 2018 Annual Data Report: Liver. Am J Transplant 2020;20 Suppl s1:193-299.

13. Kim WR, Lake JR, Smith JM, et al. Liver. Am J Transplant 2016;16 Suppl 2:69-98.

14. Adam R, Karam V, Delvart V, et al. Evolution of indications and results of liver transplantation in Europe. A report from the European Liver Transplant Registry (ELTR). J Hepatol 2012;57:675-88.

15. Zapletal C, Faust D, Wullstein C, et al. Does the liver ever age? Results of liver transplantation with donors above 80 years of age. Transplant Proc 2005;37:1182-5.

16. Pirenne J, Monbaliu D, Van Gelder F, et al. Liver transplantation using livers from septuagenarian and octogenarian donors: an underused strategy to reduce mortality on the waiting list. Transplant Proc 2005;37:1180-1.

17. Chapman WC, Vachharajani N, Collins KM, et al. Donor Age-Based Analysis of Liver Transplantation Outcomes: Short- and Long-Term Outcomes Are Similar Regardless of Donor Age. J Am Coll Surg 2015;221:59-69.

18. Grande L, Rull A, Rimola A, et al. Outcome of patients 
undergoing orthotopic liver transplantation with elderly donors (over 60 years). Transplant Proc 1997;29:3289-90.

19. Haugen CE, Bowring MG, Holscher CM, et al. Survival benefit of accepting livers from deceased donors over 70 years old. Am J Transplant 2019;19:2020-8.

20. Stewart ZA, Locke JE, Segev DL, et al. Increased risk of graft loss from hepatic artery thrombosis after liver transplantation with older donors. Liver Transpl 2009; 15:1688-95.

21. Ghinolfi D, De Simone P, Lai Q, et al. Risk analysis of ischemic-type biliary lesions after liver transplant using octogenarian donors. Liver Transpl 2016;22:588-98.

22. Saidi RF, Markmann JF, Jabbour N, et al. The faltering solid organ donor pool in the United States (2001-2010). World J Surg 2012;36:2909-13.

23. Callaghan CJ, Charman SC, Muiesan P, et al. Outcomes of transplantation of livers from donation after circulatory death donors in the UK: a cohort study. BMJ Open 2013;3:e003287.

24. Taner CB, Bulatao IG, Willingham DL, et al. Events in procurement as risk factors for ischemic cholangiopathy in liver transplantation using donation after cardiac death donors. Liver Transpl 2012;18:100-11.

25. Anstee QM, Targher G, Day CP. Progression of NAFLD to diabetes mellitus, cardiovascular disease or cirrhosis. Nat Rev Gastroenterol Hepatol 2013;10:330-44.

26. López-Velázquez JA, Silva-Vidal KV, Ponciano-Rodríguez $\mathrm{G}$, et al. The prevalence of nonalcoholic fatty liver disease in the Americas. Ann Hepatol 2014;13:166-78.

27. Spitzer AL, Lao OB, Dick AA, et al. The biopsied donor liver: incorporating macrosteatosis into high-risk donor assessment. Liver Transpl 2010;16:874-84.

28. Angele MK, Rentsch M, Hartl WH, et al. Effect of graft steatosis on liver function and organ survival after liver transplantation. Am J Surg 2008;195:214-20.

29. Ploeg RJ, D'Alessandro AM, Knechtle SJ, et al. Risk factors for primary dysfunction after liver transplantation-a multivariate analysis. Transplantation 1993;55:807-13.

30. Dutkowski P, Schlegel A, Slankamenac K, et al. The use of fatty liver grafts in modern allocation systems: risk assessment by the balance of risk (BAR) score. Ann Surg 2012;256:861-8; discussion 868-9.

31. Wong TCL, Fung JYY, Chok KSH, et al. Excellent outcomes of liver transplantation using severely steatotic grafts from brain-dead donors. Liver Transpl 2016;22:226-36.

32. Chavin KD, Taber DJ, Norcross M, et al. Safe use of highly steatotic livers by utilizing a donor/recipient clinical algorithm. Clin Transplant 2013;27:732-41.

33. Lai JC, O'Leary JG, Trotter JF, et al. Risk of advanced fibrosis with grafts from hepatitis $\mathrm{C}$ antibody-positive donors: A multicenter cohort study. Liver Transpl 2012;18:532-8.

34. Velidedeoglu E, Desai NM, Campos L, et al. The outcome of liver grafts procured from hepatitis C-positive donors. Transplantation 2002;73:582-7.

35. Northup PG, Argo CK, Nguyen DT, et al. Liver allografts from hepatitis $\mathrm{C}$ positive donors can offer good outcomes in hepatitis $\mathrm{C}$ positive recipients: a US National Transplant Registry analysis. Transpl Int 2010;23:1038-44.

36. Chhatwal J, Samur S, Bethea ED, et al. Transplanting hepatitis $\mathrm{C}$ virus-positive livers into hepatitis $\mathrm{C}$ virusnegative patients with preemptive antiviral treatment: A modeling study. Hepatology 2018;67:2085-95.

37. Cotter TG, Paul S, Sandıkçı B, et al. Increasing Utilization and Excellent Initial Outcomes Following Liver Transplant of Hepatitis C Virus (HCV)-Viremic Donors Into HCV-Negative Recipients: Outcomes Following Liver Transplant of HCV-Viremic Donors. Hepatology 2019;69:2381-95.

38. Cholongitas E, Papatheodoridis GV, Burroughs AK. Liver grafts from anti-hepatitis B core positive donors: a systematic review. J Hepatol 2010;52:272-9.

39. Wong TC, Fung JY, Cui TY, et al. Liver transplantation using hepatitis B core positive grafts with antiviral monotherapy prophylaxis. J Hepatol 2019;70:1114-22.

40. Chang MS, Olsen SK, Pichardo EM, et al. Prevention of de novo hepatitis $B$ with adefovir dipivoxil in recipients of liver grafts from hepatitis B core antibody-positive donors. Liver Transpl 2012;18:834-8.

41. Takemura N, Sugawara Y, Tamura S, et al. Liver transplantation using hepatitis B core antibody-positive grafts: review and university of Tokyo experience. Dig Dis Sci 2007;52:2472-7.

42. Emond JC, Freeman RB Jr, Renz JF, et al. Optimizing the use of donated cadaver livers: analysis and policy development to increase the application of split-liver transplantation. Liver Transpl 2002;8:863-72.

43. Superina R. To split or not to split: that is the question. Liver Transpl 2012;18:389-90.

44. Vagefi PA, Parekh J, Ascher NL, et al. Outcomes with split liver transplantation in 106 recipients: the University of California, San Francisco, experience from 1993 to 2010. Arch Surg 2011;146:1052-9.

45. Doyle MB, Maynard E, Lin Y, et al. Outcomes with split liver transplantation are equivalent to those with whole 
organ transplantation. J Am Coll Surg 2013;217:102-12; discussion 113-4.

46. Aseni P, De Feo TM, De Carlis L, et al. A prospective policy development to increase split-liver transplantation for 2 adult recipients: results of a 12-year multicenter collaborative study. Ann Surg 2014;259:157-65.

47. Lauterio A, Di Sandro S, Concone G, et al. Current status and perspectives in split liver transplantation. World J Gastroenterol 2015;21:11003-15.

48. Wachs ME, Bak TE, Karrer FM, et al. Adult living donor liver transplantation using a right hepatic lobe. Transplantation 1998;66:1313-6.

49. Shah SA, Levy GA, Greig PD, et al. Reduced mortality with right-lobe living donor compared to deceased-donor liver transplantation when analyzed from the time of listing. Am J Transplant 2007;7:998-1002.

50. Malagó M, Rogiers X, Broelsch CE. Liver splitting and living donor techniques. Br Med Bull 1997;53:860-7.

51. Ghobrial RM, Freise CE, Trotter JF, et al. Donor morbidity after living donation for liver transplantation. Gastroenterology 2008;135:468-76.

52. Middleton PF, Duffield M, Lynch SV, et al. Living donor liver transplantation--adult donor outcomes: a systematic review. Liver Transpl 2006;12:24-30.

53. Abecassis MM, Fisher RA, Olthoff KM, et al. Complications of Living Donor Hepatic Lobectomy_A Comprehensive Report. Am J Transplant 2012;12:1208-17.

54. She WH, Chok KS, Fung JY, et al. Outcomes of right-lobe and left-lobe living-donor liver transplantations using smallfor-size grafts. World J Gastroenterol 2017;23:4270-7.

55. Olthoff KM, Smith AR, Abecassis M, et al. Defining Longterm Outcomes With Living Donor Liver Transplantation in North America. Ann Surg 2015;262:465-75.

56. Thuluvath PJ, Yoo HY. Graft and patient survival after adult live donor liver transplantation compared to a matched cohort who received a deceased donor transplantation. Liver Transpl 2004;10:1263-8.

57. Abt PL, Mange KC, Olthoff KM, et al. Allograft Survival Following Adult-to-Adult Living Donor Liver Transplantation. Am J Transplant 2004;4:1302-7.

58. Schlegel A, Muller X, Kalisvaart M, et al. Outcomes of DCD liver transplantation using organs treated by hypothermic oxygenated perfusion before implantation. J Hepatol 2019;70:50-7.

59. Laing RW, Mergental H, Yap C, et al. Viability testing and transplantation of marginal livers (VITTAL) using normothermic machine perfusion: study protocol for an open-label, non-randomised, prospective, single-arm trial. BMJ Open 2017;7:e017733.

60. Mergental H, Perera MT, Laing RW, et al. Transplantation of Declined Liver Allografts Following Normothermic ExSitu Evaluation. Am J Transplant 2016;16:3235-45.

61. Jinjuvadia R, Liangpunsakul S. Trends in Alcoholic Hepatitis-related Hospitalizations, Financial Burden, and Mortality in the United States. J Clin Gastroenterol 2015;49:506-11.

62. Bertuccio P, Turati F, Carioli G, et al. Global trends and predictions in hepatocellular carcinoma mortality. J Hepatol 2017;67:302-9.

63. Mazzaferro V, Regalia E, Doci R, et al. Liver transplantation for the treatment of small hepatocellular carcinomas in patients with cirrhosis. N Engl J Med 1996;334:693-9.

64. Maggs JR, Suddle AR, Aluvihare V, et al. Systematic review: the role of liver transplantation in the management of hepatocellular carcinoma. Aliment Pharmacol Ther 2012;35:1113-34.

65. Yao FY, Ferrell L, Bass NM, et al. Liver transplantation for hepatocellular carcinoma: Expansion of the tumor size limits does not adversely impact survival. Hepatology 2001;33:1394-403.

66. Kalra A, Biggins SW. New paradigms for organ allocation and distribution in liver transplantation. Curr Opin Gastroenterol 2018;34:123-31.

67. Lunsford KE, Javle M, Heyne K, et al. Liver transplantation for locally advanced intrahepatic cholangiocarcinoma treated with neoadjuvant therapy: a prospective case-series. Lancet Gastroenterol Hepatol 2018;3:337-48.

68. Dueland S, Guren TK, Hagness M, et al. Chemotherapy or liver transplantation for nonresectable liver metastases from colorectal cancer? Ann Surg 2015;261:956-60.

69. Kumar K, King EA, Muzaale AD, et al. A Smartphone App for Increasing Live Organ Donation. Am J Transplant 2016;16:3548-53.

70. Ayorinde JOO, Saeb-Parsy K, Hossain A. Opportunities and Challenges in Using Social Media in Organ Donation. JAMA Surg 2020;155:797-8.

Cite this article as: Ahmed O, Doyle MBM. Liver transplantation: expanding the donor and recipient pool. Chin Clin Oncol 2021;10(1):6. doi: 10.21037/cco-20-212 